\title{
Effect of oral ginger on prevention of nausea and vomiting after laparoscopic cholecystectomy: a double- blind, randomized, placebo-controlled trial
}

\author{
Alireza Bameshki ${ }^{1}$, Mohammad Hasan Namaiee ${ }^{2}$, Ali Jangjoo ${ }^{3}$, Maliheh Dadgarmoghaddam ${ }^{4}$, Mohammad $^{6}$ \\ Hosein Eshaghi Ghalibaf ${ }^{5}$, Atefeh Ghorbanzadeh ${ }^{6}$, Shima Sheybani ${ }^{7}$
}

${ }^{1}$ M.D., Anesthesiologist, Associate Professor, Department of Anesthesiology, Faculty of Medicine, Mashhad University Of Medical Sciences, Mashhad, Iran

${ }^{2}$ M.D., Resident of Anesthesiology, Department of Anesthesiology, Mashhad University of Medical Sciences, Mashhad, Iran

${ }^{3}$ M.D., Surgeon, Associate Professor, Department of Surgery, Faculty of Medicine, Mashhad University of Medical Sciences, Mashhad, Iran

${ }^{4}$ M.D., Community Medicine Specialist, Assistant Professor, Department of Community Medicine, Faculty of Medicine, Mashhad University of Medical Sciences, Mashhad, Iran

${ }^{5}$ B.Sc., Anesthetist Nurse, Department of Anesthesiology, Mashhad University of Medical Sciences, Mashhad, Iran

${ }^{6}$ Medical Student, Mashhad University of Medical Sciences, Mashhad, Iran

${ }^{7}$ M.D., Cardiac Anesthesiologist, Assistant Professor, Department of Anesthesiology, Faculty of Medicine, Mashhad University of Medical Sciences, Mashhad, Iran

\section{Type of article: Original}

\begin{abstract}
Background: Postoperative nausea and vomiting (PONV) are among the most frequent complications following laparoscopic cholecystectomy. Recently, some studies have shown ginger, as an herbal medicine, to be effective and safe in PONV prevention; however, there is no evidence of its efficacy in the Iranian population.

Objective: The aim of this study was to determine the effect of oral ginger on PONV prevention after laparoscopic cholecystectomy.

Methods: This double-blind, randomized, placebo-controlled clinical trial was performed on women who were undergoing laparoscopic cholecystectomy in Imam Raza Hospital, Mashhad, Iran between April and November, 2016. Patients were divided randomly into two groups of $G$ ) intervention group ( $n=75$, received 2 capsules containing $250 \mathrm{mg}$ ginger) and $\mathrm{P}$ ) placebo group ( $\mathrm{n}=75$, received 2 placebo capsules) one hour before surgery. Nausea severity and vomiting frequency were evaluated at 2, 4, 6, and 12 hours after the operation. Data analysis was done by SPSS version 16.0 software with Chi-square test, Independent-sample-t-test, repeated measure ANOVA and Mann-Whitney U test.

Results: The two groups were homogenous in terms of age, gender and surgery duration. The severity of nausea was lower in the ginger group at the 2, 4, 6, and 12 hours after the operation; however, these differences were statically significant only at $2(\mathrm{p}=0.034)$ and 12 hours $(\mathrm{p}=0.043)$. Although the incidence of vomiting was higher in the placebo group in the 2nd and 12th hours after surgery, the number of vomiting episodes in 2, 4, 6 and 12 hours after surgery was statistically similar in the two groups $(\mathrm{p}>0.05)$. The nausea severity was significantly changed during 12 hours of study in both groups $(\mathrm{p}=0.001)$, however the nausea severity was always lower in the ginger group $(\mathrm{p}=0.078)$.

Conclusion: This study demonstrated that $500 \mathrm{mg}$ oral ginger one hour before surgery in women who were undergoing laparoscopic cholecystectomy is effective in decreasing severity of PONV.

Trial registration: The trial was registered at the Iranian Registry of Clinical Trials (http://www.irct.ir) with the Irct ID: IRCT2016122222218N2.

\section{Corresponding author:}

Assistant Professor Dr. Shima Sheybani, Department of Anesthesiology, Faculty of Medicine, Mashhad University of Medical Sciences, Mashhad Iran. Tel: +98.5137647230, Email: sheybanish@mums.ac.ir

Received: August 30, 2017, Accepted: December 27, 2017, Published: February 2018

iThenticate screening: December 25, 2017, English editing: January 14, 2018, Quality control: January 15, 2018

This article has been reviewed / commented by four experts

(C) 2018 The Authors. This is an open access article under the terms of the Creative Commons Attribution-NonCommercialNoDerivs License, which permits use and distribution in any medium, provided the original work is properly cited, the use is non-commercial and no modifications or adaptations are made.
\end{abstract}


Funding: The study was financially supported by Deputy of Research of Mashhad University of Medical Sciences.

Keywords: Nausea, Vomiting, Postoperative Nausea and Vomiting, Ginger, Cholecystectomy, Laparoscopic

\section{Introduction}

Postoperative nausea and vomiting (PONV) are among the most frequent adverse effects after general anesthesia (1). This side issue is seen after almost all surgeries, including laparoscopic surgeries with an incidence of $28 \%$ to $75 \%(2,3)$. Post-operative uncontrolled PONV can lead to major complications such as dehydration, wound dehiscence, electrolyte disturbance, high blood pressure, aspiration pneumonitis, and consequently, delay in discharge, increased healthcare costs and patient dissatisfaction (4-6). Although different anti-emetic medications are currently used for the treatment of PONV, such as droperidol, metoclopramide, and ondansetron (7, 8), these agents are also often associated with a variety of side effects including long QT syndrome and extrapyramidal symptoms $(7,9)$. Thus, investigations for finding newer medications and procedures with fewer side effects are still ongoing (10-12). Nowadays, herbal medicines have been commonly used for treatment and prevention of different diseases, for the reason of safety, efficacy, availability, affordability, and minimal side effects (13, 14). According to World Health Organization (WHO) reports, more than two thirds of people around the world use herbal medicines, such as ginger, as a nonmedical antinausea treatment (12). Ginger (Zingiber officinale Roscoe), as an herbal medicine, has been considered as a nonpharmacological option in several conditions such as gastro-intestinal complaints, arthritis, cancer prevention, and atherosclerosis (15). Moreover, ginger has been recently recommended as a safe agent, due to its medicinal properties related to gingerols and shogaols, in various circumstances such as morning sickness, motion sickness, pregnancy and chemotherapy induced nausea, and PONV (15-17). The mechanism of ginger action as an antiemetic agent is still not clear, yet some reports demonstrated that it has direct effect against serotonin receptor $(14,18,19)$. Although different clinical studies have shown the anti-emetic effect of ginger for prevention of PONV $(11,20)$, there were also findings against its efficacy after laparoscopic surgeries (21). Moreover, according to the latest review article, "further studies are required before firm recommendations for ginger use can be made" (11). Besides, considering the varying responses to medicines in patients with varied ethnicity and race, the clinical effectiveness of ginger in postoperative management of PONV should be evaluated in different countries before its application (22). According to our knowledge, few studies have demonstrated the clinical efficacy of ginger for prevention of PONV after surgery in the Iranian population; however, the evidence for cholecystectomy is completely limited (20, 23-26). Moreover, the previous studies have investigated the effect of a high dose of ginger, mostly $1 \mathrm{gr}$, on PONV prevention, and the question if ginger is still effective in lower doses is still unclear (27). The aim of this study is to determine the effect of oral ginger on the prevention of PONV after laparoscopy in the early post-operative period.

\section{Material and Methods}

\subsection{Trial design and setting}

This double-blind, randomized, placebo-controlled clinical trial was performed on female patients who electively underwent laparoscopic cholecystectomy at the Department of General Surgery, Imam Raza Hospital, Mashhad, Iran, between April 2016 and November, 2016.

\subsection{Selection criteria}

Inclusion criteria were: 1) age less than 65 years old, 2) body mass index of lower than $35 \mathrm{~kg} / \mathrm{m} 2$, and 3) ASA class I or II. Patients were excluded if they have 1) history of smoking, addiction and alcohol usage, 2) chronic nausea and vomiting (NAV) , 3) an NAV during the last 24 hours, 4) history of PONV , 5) motion sickness disease, 6) vestibular diseases, 7) anti-emetic agents' usage before surgery, 8) prolonged surgery (more than 90 minutes), 9) urgent surgery, 10) history of chronic diseases such as diabetes, kidney diseases, liver disease, heart diseases, and 11) pregnancy.

\subsection{Sampling}

The sample size was estimated to be 62 subjects in two groups of 31 . This sample size was calculated based on the results of previous meta-analysis (27) by assuming the test power of $80 \%$ and a confidence level of $95 \%$ and using the following formula: $n=\left(Z_{1-\alpha / 2}+Z_{1-\beta}\right)^{2}\left(\left(P_{1}\left(1-P_{1}\right)+P 2\left(1-P_{2}\right)\right) /\left(P_{1}-P_{2}\right)^{2}\right.$, Where: $n=$ Sample size, $Z_{1-\alpha / 2}=1.96 . \alpha=5 \%$ for two-sided test. $\mathrm{Z}_{1-\beta}=0.842, \beta=20 \%$ (test power $=80 \%$ ), and $\mathrm{P}=$ probability of the main outcome. Simple random sampling was used for reaching the adequate number of patients by means of computer generated codes. 


\subsection{Randomization and blinding}

Patients were randomly allocated to receive ginger (G group) or placebo (P group) on a 1:1 ratio. A researcher who had no responsibility in the study protocol, did the randomization. The randomization sequence was created by computer-generated random numbers. For this purpose, the numbered envelopes that contained the name of the agents (ginger or placebo) were used. Medications were delivered to the patients by a researcher who was not aware of anti-emetic agents. Moreover, all the baseline characteristics including age, body mass index, surgery duration, and outcomes were recorded by the researcher without knowledge to groupings. Patients were also not aware about their anti-emetic agents. So, it was a double blinded placebo controlled clinical trial.

\subsection{Allocation and Interventions}

Group G received 2 capsules of $250 \mathrm{mg}$ ginger (Zintoma Herbal Capsule, Gol Daru Company, Iran). Group P received 2 isoshape, isosmell, and isocolor capsules as placebo. Both groups received their medications one hour prior to surgeries. After a routine preparation, anesthesia was performed in the same manner in all patients. Participants underwent fasting diet for 8 hours before surgery. Patients received midazolam $0.04 \mathrm{mg} / \mathrm{kg}$, fentanyl $3 \mu \mathrm{g} / \mathrm{kg}$, as premedication, and crystalloid fluid $10 \mathrm{cc} / \mathrm{kg}$ before induction of anesthesia and then underwent induction with $2 \mathrm{mg} / \mathrm{kg}$ propofol and atracorium $0.5 \mathrm{mg} / \mathrm{kg}$. Anesthesia was maintained with propofol 100 $200 \mu \mathrm{g} / \mathrm{kg} / \mathrm{min}$. During operation, blood pressure, heart rate, electrocardiogram (ECG), SPO2, end-tidal carbon dioxide (Etco2) was monitored. Decrease or increase of heart rate and blood pressure over $20 \%$ was treated with $20 \%$ decrease or increase in dose of propofol. Muscle relaxation was done with atracorium $0.04-0.02 \mathrm{mg} / \mathrm{kg}$. Following the end of surgery, patients were extubated and transferred to the recovery room. Patients received 30-40 $\mathrm{cc} / \mathrm{kg}$ of crystalloid fluid during the next 24 hours after surgery. All patients received a single approach for laparoscopic cholecystectomy operated by one single surgeon.

\subsection{Nausea and Vomiting}

The severity of nausea and the number of episodes of vomiting in 2, 4,6 and 12 hours after surgery were evaluated and recorded. In order to evaluate severity of nausea, the 11-point numerical rating scale (NRS) was used; the patients were asked to rate the severity of their nausea from zero (no feeling of nausea) to 10 (the highest feeling of nausea). Patients were informed about the NRS in relation to the nausea feeling. Vomiting was defined as severe mobility of the gastrointestinal tract which leads to the forceful exit of the contents of the digestive tract from the mouth. Aside from the vomiting numbers in each period of time, the incidence of vomiting, in each 4 periods of time were recorded. Every patient who showed the side effects of the used drug were excluded and underwent proper treatment. Intravenous ondansetron $4 \mathrm{mg}$ was given to patients who complained of post-operative nausea (NRS $>4$ ) and vomiting despite receiving a dose of prophylactic antiemetic medication during the operation, and then the patients were assessed after half an hour.

\subsection{Outcomes}

The first outcome of this study was the compared severity of nausea in patients receiving ginger and placebo undergoing laparoscopic cholecystectomy. The second outcome was the compared incidence of vomiting and the number of vomiting in each period of time between these two groups.

\subsection{Ethics}

This study was approved by the Ethical Research Committee of Mashhad University of Medical Sciences (Code: IR,MUMS.sm.REC.1394.358). This study was registered in the Iranian Registry of Clinical Trials (irct.ir) with the ID: IRCT2016122222218N2. All participants were informed about the aims and the nature of current study, and each participant provided her written consent form prior to the study. All the participants' information was kept confidential. Patients were eligible to leave the study at any phase of the research program.

\subsection{Statistical methods}

The data were analyzed using IBM SPSS Statistics for Windows (Version 19.0. Armonk, NY: IBM Corp.). First, the normality of the variables' distribution was examined using the K-S test. Quantitative variables were reported with mean \pm standard deviation and qualitative variables with frequency and percentage. The severity of PONV was compared between the two groups by independent-samples t-test or and Mann-Whitney $U$ test and the incidence of vomiting with Chi-square. The repeated measure ANOVA was recruited to compare the changes trend in nausea severity. P-value $<0.05$ was considered as significant. 


\section{Results}

\subsection{Baseline Characteristics}

Initially, a total of 164 female participants with a mean age of $39.9 \pm 11.6$ years were assumed eligible for the study. Fourteen participants were excluded from the study and finally this study was conducted on 150 patients in two groups of $G(n=75)$ and $P(n=75)$ (Figure 1). There was no significant difference between two groups in terms of age, body mass index, and surgery duration (Table 1).

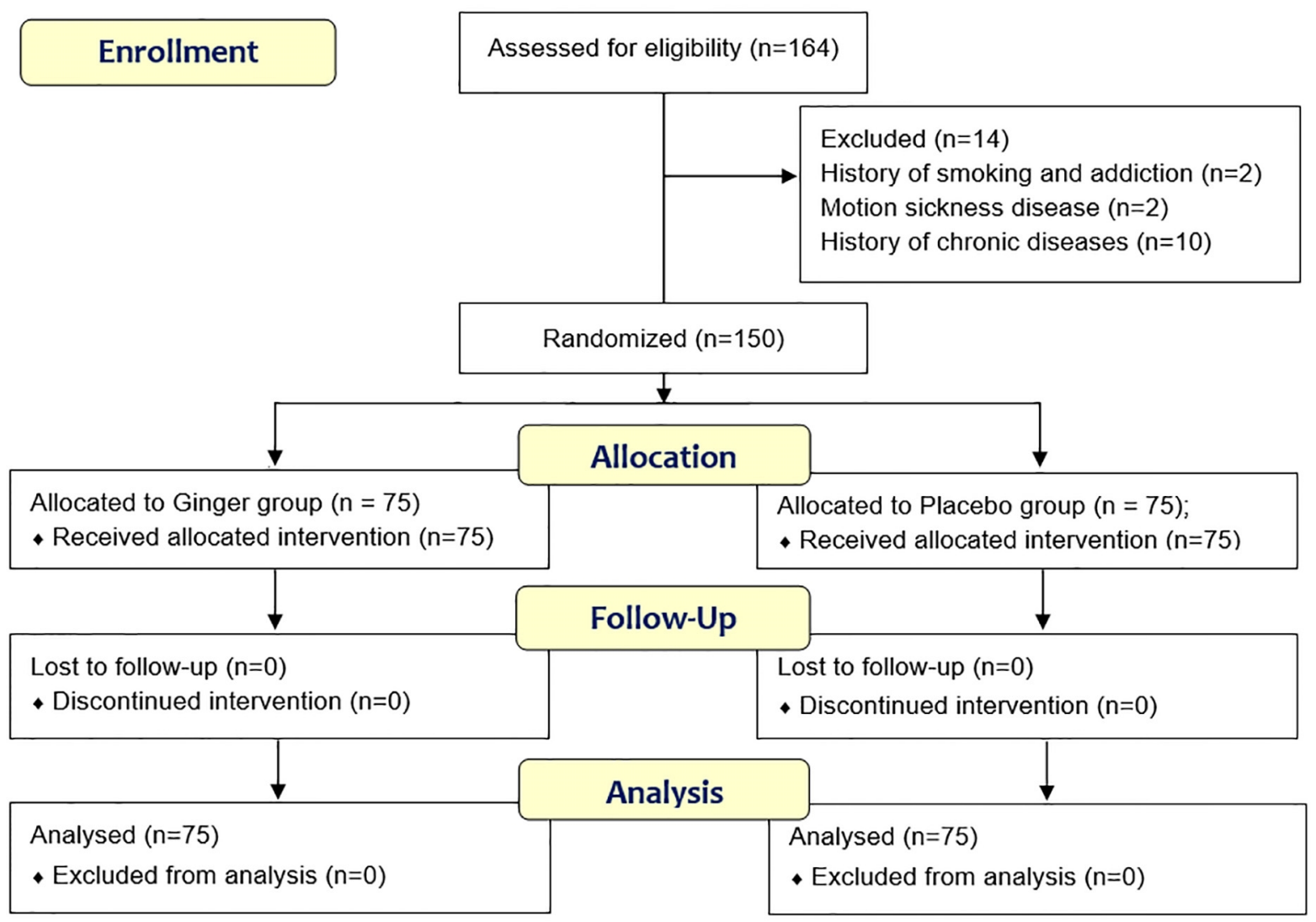

Figure 1. Follow-up diagram of patients (According to consort statement)

Table 1. Baseline characteristics in patients receiving ginger and placebo undergoing laparoscopic cholecystectomy

\begin{tabular}{|l|l|l|l|}
\hline Variable, mean \pm SD & Placebo $(\mathrm{n}=75)$ & Ginger $(\mathrm{n}=75)$ & $\mathrm{p}$-value \\
\hline Age, years & $32.8 \pm 10.6$ & $41.7 \pm 12.4$ & $0.093^{\mathrm{a}}$ \\
\hline Weigh, kg & $68.2 \pm 11.9$ & $65.6 \pm 9.1$ & $0.137^{\mathrm{b}}$ \\
\hline Surgery duration, min & $68 \pm 15.4$ & $69.3 \pm 13.7$ & $0.627^{\mathrm{a}}$ \\
\hline
\end{tabular}

a: Mann-Whitney U test; b: independent-samples t-test

\subsection{Nausea and Vomiting}

The severity of nausea was lower in the ginger group than the placebo group, but it was only significant between the two groups in 2 hours ( $\mathrm{p}=0.034)$ and 12 hours $(0.043)$ after surgery (Table 2$)$. The nausea severity was significantly changed during 12 hours of study in both groups $(\mathrm{P}=0.001)$, however the nausea severity was always lower in the ginger group $(\mathrm{p}=0.078)$ (Figure 2). The incidence of vomiting in the ginger group was also lower in comparison with the placebo group; however, only in the $2^{\text {nd }}(\mathrm{p}=0.017)$ and $12^{\text {th }}(\mathrm{p}=0.044)$ hours after surgery was it statically significant (Table 3). Moreover, there was no difference between two groups regarding the number of vomiting in 2 , 4, 6, and 12 hours after surgery (Table 4). Thirty-one participants (41.3\%) of group G and 35 participants (62.6\%) of group $\mathrm{P}$ received ondansetron for their PONV during the study $(\mathrm{p}=0.511)$. 
Table 2. Severity of nausea in patients receiving ginger and placebo undergoing laparoscopic cholecystectomy

\begin{tabular}{|l|l|l|l|}
\hline Time after surgery, $\mathrm{NRS}^{\mathrm{a}}$, mean \pm SD & Placebo $(\mathrm{n}=75)$ & Ginger $(\mathrm{n}=75)$ & $\mathrm{p}$-value \\
\hline 2 hours & $2.9 \pm 2.8$ & $2.0 \pm 2.7$ & 0.034 \\
\hline 4 hours & $3.2 \pm 2.6$ & $2.8 \pm 2.7$ & 0.352 \\
\hline 6 hours & $2.0 \pm 2.7$ & $1.8 \pm 2.4$ & 0.622 \\
\hline 12 hours & $1.8 \pm 0.8$ & $0.4 \pm 1.4$ & 0.043 \\
\hline
\end{tabular}

NRS: Numerical Rating Scale (0-10)

Table 3. Incidence of vomiting in patients receiving ginger and placebo undergoing laparoscopic cholecystectomy

\begin{tabular}{|l|l|l|l|}
\hline Time after surgery, $\mathrm{n}(\%)$ & Placebo $(\mathrm{n}=75)$ & Ginger $(\mathrm{n}=75)$ & $\mathrm{p}$-value \\
\hline 2 hours & $46(61.3)$ & $33(44.0)$ & 0.017 \\
\hline 4 hours & $50(66.6)$ & $43(57.3)$ & 0.293 \\
\hline 6 hours & $32(42.6)$ & $29(38.6)$ & 0.722 \\
\hline 12 hours & $15(20.0)$ & $6(8.0)$ & 0.044 \\
\hline
\end{tabular}

Table 4. Number of vomiting in each period of time in patients receiving ginger and placebo undergoing

\begin{tabular}{|l|l|l|l|}
\hline Time after surgery, mean \pm SD & Placebo $(\mathrm{n}=75)$ & Ginger $(\mathrm{n}=75)$ & $\mathrm{p}$-value \\
\hline 2 hours & $0.4 \pm 0.9$ & $0.3 \pm 0.7$ & 0.352 \\
\hline 4 hours & $0.6 \pm 0.8$ & $0.6 \pm 0.9$ & 0.631 \\
\hline 6 hours & $0.7 \pm 0.3$ & $0.4 \pm 0.7$ & 0.375 \\
\hline 12 hours & $0.2 \pm 0.1$ & $0.1 \pm 0.3$ & 0.985 \\
\hline
\end{tabular}

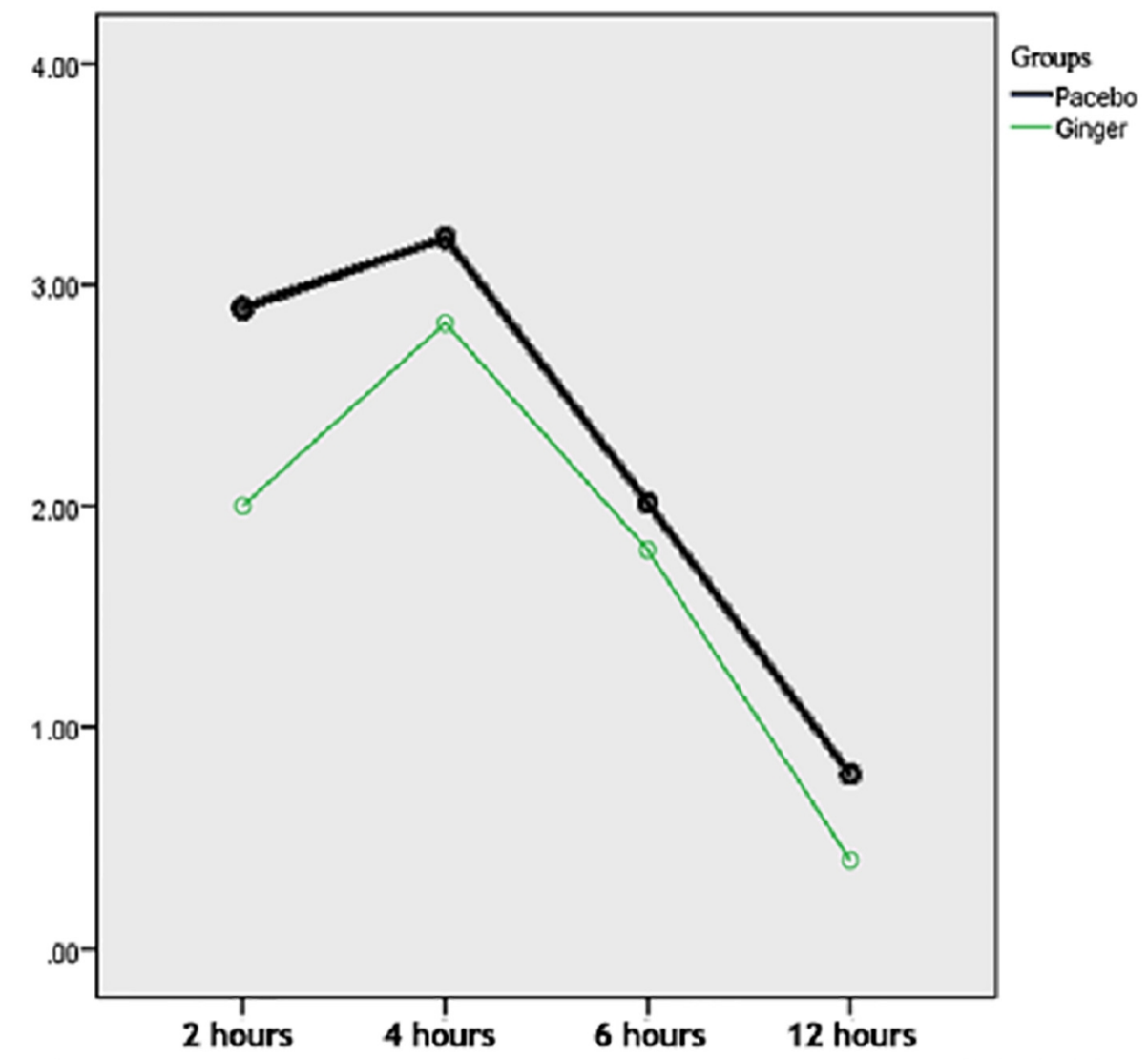

Figure 2. The differences of severity of nausea in patients receiving ginger and placebo undergoing laparoscopic cholecystectomy based on the numerical rating scale (0-10) assessment (vertical axis) during $12 \mathrm{~h}$ (horizontal axis) after surgery. 


\section{Discussion}

This study was conducted to evaluate the efficacy of ginger for PONV prevention in patients undergoing laparoscopic cholecystectomy, and the main findings revealed that this agent seems to be clinically and sometimes, statistically effective. PONV is one of the most annoying complications following general anesthesia, mainly in laparoscopic surgery $(28,29)$. Also in our study, according to the time of data recording, the incidence of PONV was somehow similar to the previous studies, around $20-70 \%$ (1). Interestingly, this incidence was around $10 \%$ to $50 \%$ in our patients receiving ginger; which showed a reduction of about $10 \%$ PONV. Although, only in the 2 nd and 12th hours after operations, the differences between two groups of ginger and placebo were statistically significant, but we could find a lower incidence of PONV in all 4 points of data entry in the ginger group, which was clinically meaningful. We did not only compare the PONV incidence between the two groups, we compared the severity of nausea and the frequency of vomiting, which supported the idea of the preventive effect of ginger in PONV. Although the mechanism of ginger action on the PONV prevention is not clear yet, anti-serotoninergic and serotonergic 5-HT3 effect of ginger extract, as well as M3 and 5-HT4 receptors antagonisms, are the possible ways of action in this aspect (30). In our study, based on both quantitative and qualitative analyses, patients who received ginger had lower complication in terms of PONV. Although, most of the available studies are in line with our findings (23-25, 31), a few studies disagreed with our results (32-34). Montazeri et al. have showed that 4 capsules containing $250 \mathrm{mg}$ of ginger, compared with placebo given one hour before surgery in patients who had undergone surgical procedure, significantly reduced the mean nausea score at 2 hours after surgery (35). But similar to our study, it had no significant effect on nausea at 4 and 6 hours after surgery. In another study which was performed by Nanthakomon et al., ginger was effective significantly on reducing nausea at 2 and 6 hour after gynecologic surgery (36). In a Kalava et al. study, one gr of ginger capsule was only significant effective on decreasing the number of episodes of intraoperative nausea after elective cesarean-section; but it had no effect on PONV reduction (37). Another study also showed that ginger had a significant effect on nausea only, and it had no effect on vomiting (35). Other similar studies which were performed by Apariman et al. and Phillips et al. reported that ginger (1.5 gm and 1 gm, respectively) was post operatively effective in reducing nausea and vomiting compared with placebo (38). Also, Hosseini et al. investigated the effect of drops of ginger on PONV either in open or laparoscopic surgeries, and reported that ginger was significantly effective on reducing PONV (25). On the other hand, a meta-analysis on six different clinical trials showed that ginger had no antiemetic impact on PONV setting (32). Also, Arfeen et al. randomized 108 women who received ginger $0.5 \mathrm{gm}$, ginger $1 \mathrm{gm}$, and placebo before laparoscopic surgery; showing that the difference between ginger and placebo groups considering PONV was not significant (39). Furthermore, Eberhart et al. did not show any benefits of ginger for the prevention of PONV after laparoscopic surgery (34).

It seems that a variety of factors lead to the similarity or differences between our findings and the other studies. First of all, we believe that a different regimen of ginger was one of the possible causes. Most of the previous studies had investigated a high dose of ginger, more than or equal to $1 \mathrm{gr}$, but in our study and the Soltani et al. study, a lower dose of ginger, $(500 \mathrm{mg})$ was prescribed $(23,24,31)$. Moreover, we have compared ginger versus placebo, however, some other studies have evaluated ginger versus ondansetron or some other anti-emetic agents (1, 11). Different races, different times of data entry, and of course different methods of assessment of PONV were the other causes of variances between studies $(20,24,27,40)$. One of the biggest limitations of our study, was referred to our study population. This study was conducted on one gender, only women, since it was stablished that female gender is a risk factor for a higher rate of PONV. In this regard, we cannot extend our findings to whole population of patients undergoing laparoscopic cholecystectomy. Moreover, our study was a single center study; which has limited the power of our findings. Lastly, we did not measure some other factors such as pain, and their possible effects on PONV.

\section{Conclusions}

In the current study, we used $500 \mathrm{mg}$ of ginger one hour before laparoscopic cholecystectomy, and the findings reveled an optimal prevention of PONV. However, we believe that the use of a higher dose of ginger in combination with other antiemetic drugs could be more effective in reducing PONV. Although ginger is known as an effective, safe, and available agent in prevention of PONV, more clinical trials in different clinical settings are required for finding the most effective dosage.

\section{Acknowledgments:}

This paper was extracted from an anesthesiology residency thesis at Mashhad University of Medical Sciences in Mashhad, Iran (Thesis Code: 4810-T). 


\section{Trial Registration:}

The trial was registered at the Iranian Registry of Clinical Trials (http://www.irct.ir) with the Irct ID: IRCT2016122222218N2

\section{Funding:}

This study was financially supported by the Deputy of Research of Mashhad University of Medical Sciences as a research project (Ref. no.: 941049)

\section{Conflict of Interest:}

There is no conflict of interest to be declared.

\section{Authors' contributions:}

All authors contributed to this project and article equally. All authors read and approved the final manuscript.

\section{References:}

1) Cao $\mathrm{X}$, White $\mathrm{PF}, \mathrm{Ma} \mathrm{H}$. An update on the management of postoperative nausea and vomiting. Journal of Anesthesia. 2017: 1-10. doi: 10.1007/s00540-017-2363-x.

2) Karanicolas PJ, Smith SE, Kanbur B, Davies E, Guyatt GH. The impact of prophylactic dexamethasone on nausea and vomiting after laparoscopic cholecystectomy: a systematic review and meta-analysis. Annals of surgery. 2008; 248(5): 751-62. doi: 10.1097/SLA.0b013e3181856024. PMID: 18948802.

3) Beattie WS, Lindblad T, Buckley DN, Forrest JB. The incidence of postoperative nausea and vomiting in women undergoing laparoscopy is influenced by the day of menstrual cycle. Can J Anaesth. 1991; 38(3): 298-302. doi: 10.1007/BF03007618. PMID: 1828016.

4) Eberhart LH, Frank S, Lange H, Morin AM, Scherag A, Wulf H, et al. Systematic review on the recurrence of postoperative nausea and vomiting after a first episode in the recovery room-implications for the treatment of PONV and related clinical trials. BMC anesthesiology. 2006; 6(1): 14. doi: 10.1186/14712253-6-14. PMID: 17166262, PMCID: PMC1712223.

5) Watcha MF, White PF. Postoperative nausea and vomiting. Its etiology, treatment, and prevention. Anesthesiology. 1992; 77(1): 162-84. doi: 10.1097/00000542-199207000-00023.

6) Gan TJ. Risk factors for postoperative nausea and vomiting. Anesthesia \& Analgesia. 2006; 102(6): 188498. doi: 10.1213/01.ANE.0000219597.16143.4D. PMID: 16717343.

7) Kovac AL. Prevention and treatment of postoperative nausea and vomiting. Drugs. 2000; 59(2): 213-43. doi: 10.2165/00003495-200059020-00005. PMID: 10730546.

8) Korttila K, Kauste A, Auvinen J. Comparison of domperidone, droperidol, and metoclopramide in the prevention and treatment of nausea and vomiting after balanced general anesthesia. Anesthesia \& Analgesia. 1979; 58(5): 396-400. doi: 10.1213/00000539-197909000-00010.

9) Hafizi L, Kiafar M, Shamloo AS, Andalibizadeh S, Nouri M, Zirak N. Comparison of the Efficacy of Midazolam Vs. Ondansetron in Preventing Post Operative Nausea and Vomiting in Gynecologic Laparoscopic Surgeries:Double-blinded Randomized Clinical Trial Study. Science Journal of Medicine and Clinical Trials. 2013; 2013. doi: 10.7237/sjmct/178.

10) Stott A. Examining the efficacy of stimulating the PC6 wrist acupuncture point for preventing postoperative nausea and vomiting: A Cochrane review summary. International journal of nursing studies. 2016; 64: 139-41. doi: 10.1016/j.jinurstu.2016.07.004. PMID: 27817841.

11) Marx W, Kiss N, Isenring L. Is ginger beneficial for nausea and vomiting? An update of the literature. Current opinion in supportive and palliative care. 2015; 9(2): 189-95. doi: 10.1097/SPC.0000000000000135. PMID: 25872115.

12) Girard N. Evidence appraisal of Seidi J, Ebnerasooli S, Shahsawari S, Nzarian S. The influence of oral ginger before operation on nausea and vomiting after cataract surgery under general anesthesia: a doubleblind placebo-controlled randomized clinical trial. AORN j. 2017; 105(6): 628-33. DOI: 10.1016/j.aorn.2017.04.014. PMID: 28554360.

13) Loya AM, González-Stuart A, Rivera JO. Prevalence of polypharmacy, polyherbacy, nutritional supplement use and potential product interactions among older adults living on the United States-Mexico border. Drugs \& aging. 2009; 26(5): 423-36. doi: 10.2165/00002512-200926050-00006. PMID: 19552494.

14) Cohen PA, Ernst E. Safety of herbal supplements: a guide for cardiologists. Cardiovascular therapeutics. 2010; 28(4): 246-53. doi: 10.1111/j.1755-5922.2010.00193.x. PMID: 20633025. 
15) Singletary K. Ginger: an overview of health benefits. Nutrition Today. 2010; 45(4): 171-83. doi: 10.1097/NT.0b013e3181ed3543.

16) Palatty PL, Haniadka R, Valder B, Arora R, Baliga MS. Ginger in the prevention of nausea and vomiting: a review. Critical reviews in food science and nutrition. 2013; 53(7): 659-69. doi: 10.1080/10408398.2011.553751. PMID: 23638927.

17) Haniadka R, Saldanha E, Sunita V, Palatty PL, Fayad R, Baliga MS. A review of the gastroprotective effects of ginger (Zingiber officinale Roscoe). Food \& function. 2013; 4(6): 845-55. doi: 10.1039/c3fo30337c. PMID: 23612703.

18) Zick SM, Ruffin MT, Lee J, Normolle DP, Siden R, Alrawi S, et al. Phase II trial of encapsulated ginger as a treatment for chemotherapy-induced nausea and vomiting. Supportive care in cancer. 2009; 17(5): 563 72. doi: 10.1007/s00520-008-0528-8. PMID: 19005687, PMCID: PMC4131259.

19) Thomson M, Corbin R, Leung L. Effects of ginger for nausea and vomiting in early pregnancy: a metaanalysis. The Journal of the American Board of Family Medicine. 2014; 27(1): 115-22. doi: 10.3122/jabfm.2014.01.130167. PMID: 24390893.

20) Seidi J, Ebnerasooli S, Shahsawari S, Nzarian S. The Influence of Oral Ginger before Operation on Nausea and Vomiting after Cataract Surgery under General Anesthesia: A double-blind placebo-controlled randomized clinical trial. Electron physician. 2017; 9(1): 3508-14. doi: 10.19082/3508. PMID: 28243400, PMCID: PMC5308488.

21) Eberhart LH, Mayer R, Betz O, Tsolakidis S, Hilpert W, Morin AM, et al. Ginger does not prevent postoperative nausea and vomiting after laparoscopic surgery. Anesthesia and analgesia. 2003; 96(4): 995 8. doi: 10.1213/01.ANE.0000055818.64084.41. PMID: 12651648.

22) Burroughs VJ, Maxey RW, Levy RA. Racial and ethnic differences in response to medicines: towards individualized pharmaceutical treatment. Journal of the National Medical Association. 2002; 94(10 Suppl): 1. PMID: 12401060, PMCID: PMC2594139.

23) Ozgoli G, Goli M, Simbar M. Effects of ginger capsules on pregnancy, nausea, and vomiting. J Altern Complement Med. 2009; 15(3): 243-6. doi: 10.1089/acm.2008.0406. PMID: 19250006.

24) Soltani E, Jangjoo A, Aghaei MA, Dalili A. Effects of preoperative administration of ginger (Zingiber officinale Roscoe) on postoperative nausea and vomiting after laparoscopic cholecystectomy. Journal of Traditional and Complementary Medicine. 2017. doi: 10.1016/j.jtcme.2017.06.008.

25) Hosseini FS, Adib-Hajbaghery M. Ginger essence effect on nausea and vomiting after open and laparoscopic nephrectomies. Nursing and midwifery studies. 2015; 4(2). doi: 10.17795/nmsjournal28625. PMID: 26339671, PMCID: PMC4557412.

26) Adib-Hajbaghery M, Hosseini FS. Investigating the effects of inhaling ginger essence on post-nephrectomy nausea and vomiting. Complementary therapies in medicine. 2015; 23(6): 827-31. doi: 10.1016/j.ctim.2015.10.002. PMID: 26645524.

27) Chaiyakunapruk N, Kitikannakorn N, Nathisuwan S, Leeprakobboon K, Leelasettagool C. The efficacy of ginger for the prevention of postoperative nausea and vomiting: a meta-analysis. American journal of obstetrics and gynecology. 2006; 194(1): 95-9. doi: 10.1016/j.ajog.2005.06.046. PMID: 16389016.

28) Khalaj AR, Miri SR, Porlashkari M, Mohammadi A. Prophylactic Anti-Emetic Effect of Dexamethasone and Metoclopramide on the Nausea and Vomiting Induced by Laparoscopic Cholecystectomy: A Randomized, Double Blind, Placebo-Controlled Trial. Journal of Minimally Invasive Surgical Sciences. 2013; 2(3): 18-22.

29) Nesek-Adam V, Grizelj-Stojčić E, Rašić Ž, Čala Z, Mršić V, Smiljanić A. Comparison of dexamethasone, metoclopramide, and their combination in the prevention of postoperative nausea and vomiting after laparoscopic cholecystectomy. Surgical endoscopy. 2007; 21(4): 607-12. doi: 10.1007/s00464-006-9122-7. PMID: 17285386.

30) Ali BH, Blunden G, Tanira MO, Nemmar A. Some phytochemical, pharmacological and toxicological properties of ginger (Zingiber officinale Roscoe): a review of recent research. Food and chemical Toxicology. 2008; 46(2): 409-20. doi: 10.1016/j.fct.2007.09.085. PMID: 17950516.

31) Mandal P, Das A, Majumdar S, Bhattacharyya T, Mitra T, Kundu R. The efficacy of ginger added to ondansetron for preventing postoperative nausea and vomiting in ambulatory surgery. Pharmacognosy research. 2014; 6(1): 52. doi: 10.4103/0974-8490.122918. PMID: 24497743, PMCID: PMC3897009.

32) Morin A, Betz O, Kranke P, Geldner G, Wulf H, Eberhart L. Is ginger a relevant antiemetic for postoperative nausea and vomiting? Anasthesiologie, Intensivmedizin, Notfallmedizin, Schmerztherapie: AINS. 2004; 39(5): 281-5. PMID: 15156419. 
33) Care AI. A double-blind randomized controlled trial of ginger for the prevention of postoperative nausea and vomiting. Anaesthesia and intensive care. 1995; 23(4).

34) Eberhart LH, Mayer R, Betz O, Tsolakidis S, Hilpert W, Morin AM, et al. Ginger does not prevent postoperative nausea and vomiting after laparoscopic surgery. Anesthesia \& Analgesia. 2003; 96(4): 995-8. doi: 10.1213/01.ANE.0000055818.64084.41.

35) Montazeri AS, Raei M, Hamidzadeh A, Hamzekhani M, Soozani A, Kalatejari M, et al. Evaluation the effect of ginger on postoperative nausea and vomiting. Danesh and Tandorosti Journal. 2012; 7(3): 118-23.

36) Nanthakomon T, Pongrojpaw D. The efficacy of ginger in prevention of postoperative nausea and vomiting after major gynecologic surgery. J Med Assoc Thai. 2006; 89(Suppl 4): S130-6. PMID: 17725149.

37) Kalava A, Darji SJ, Kalstein A, Yarmush JM, Schianodi Cola J, Weinberg J. Efficacy of ginger on intraoperative and postoperative nausea and vomiting in elective cesarean section patients. Eur J Obstet Gynecol Reprod Biol. 2013; 169(2): 184-8. doi: 10.1016/j.ejogrb.2013.02.014. PMID: 23510951.

38) Apariman S, Ratchanon S, Wiriyasirivej B. Effectiveness of ginger for prevention of nausea and vomiting after gynecological laparoscopy. Journal-Medical Association of Thailand. 2006; 89(12): 2003. PMID: 17214049.

39) Arfeen Z, Owen H, Plummer JL, Ilsley AH, Sorby-Adams RA, Doecke CJ. A double-blind randomized controlled trial of ginger for the prevention of postoperative nausea and vomiting. Anaesthesia and intensive care. 1995; 23(4): 449-52. PMID: 7485935.

40) Lee YR, Shin HS. Effectiveness of Ginger Essential Oil on Postoperative Nausea and Vomiting in Abdominal Surgery Patients. The Journal of Alternative and Complementary Medicine. 2017; 23(3): 196200. doi: 10.1089/acm.2015.0328. PMID: 27841938. 